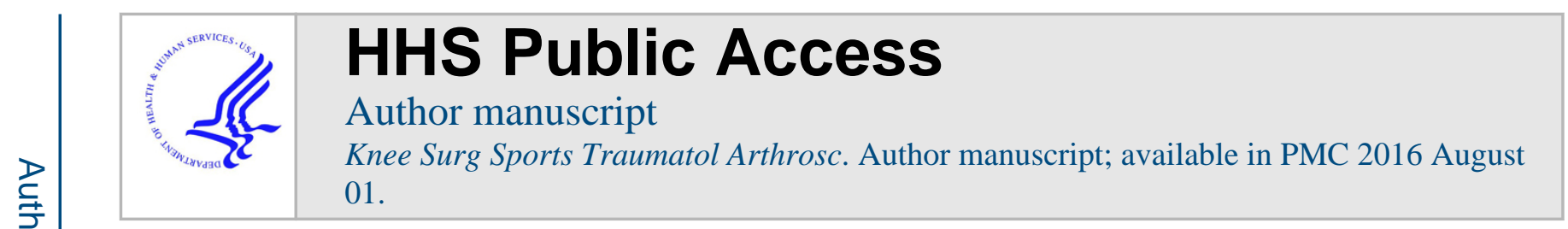

Published in final edited form as:

Knee Surg Sports Traumatol Arthrosc. 2015 August ; 23(8): 2339-2348. doi:10.1007/s00167-014-3060-z.

\title{
Patient Demographics and Surgical Characteristics in ACL Revision: A Comparison of French, Norwergian, and North American Cohorts
}

\author{
Robert A. Magnussen, MD ${ }^{1,2}$, Christophe Trojani, MD ${ }^{3}$, Lars-Petter Granan, MD, PhD ${ }^{4}$, \\ MARS Group ${ }^{*}$, SFA Revision ACL Group, Philippe Neyret, MD ${ }^{5}$, Philippe Colombet, MD ${ }^{6}$, \\ Lars Engebretsen, MD, PhD ${ }^{7}$, Rick W. Wright, $\mathbf{M D}^{8}$, and Christopher C. Kaeding, $\mathbf{M D}^{1,2}$ \\ ${ }^{1}$ Department of Orthopaedics, The Ohio State University, Columbus, OH, USA \\ ${ }^{2}$ Sports Health and Performance Institute, The Ohio State University, Columbus, $\mathrm{OH}$, USA \\ ${ }^{3}$ Department of Orthopaedic Surgery and Sports Traumatology, Hôpital de L'Archet, University of \\ Nice-Sophia Antipolis, Nice, France \\ ${ }^{4}$ Department of Physical Medicine and Rehabilitation, Oslo University Hospital, Oslo, Norway \\ ${ }^{5}$ Department of Orthopaedic Surgery, Hôpital de la Croix-Rouse, Lyon, France \\ 69 Rue Jean Moulin, Merignac, France \\ ${ }^{7}$ Department of Orthopaedics, Oslo University Hospital, Oslo, Norway \\ ${ }^{8}$ Department of Orthopaedic Surgery, Washington University, Chesterfield, MO, USA
}

\begin{abstract}
Purpose-The goal of this paper is to compare patient factors, intra-operative findings, and surgical techniques between patients followed in large cohorts in France, Norway, and North America.

Methods-Data collected on 2286 patients undergoing revision ACLR were obtained. These data included 1216 patients enrolled in the Multicenter ACL Revision Study (MARS) in North America, 793 patients undergoing revision ACLR and recorded in the Norwegian Knee Ligament Registry (NKLR), and 277 patients recorded in the revision ACL database of the Société Française d'Arthroscopie (SFA) in France. Data collected from each database included patient demographics (age, sex, height, and weight), graft choice and reason for failure of the primary ACLR, time from primary to revision ACLR, pre-revision patient-reported outcome scores (KOOS, subjective IKDC), associated intra-articular findings and treatments at revision, and graft choice for revision reconstruction.
\end{abstract}

Results-Patient demographics in the three databases were relatively similar. Graft choice for primary and revision ACLR varied significantly, with more allografts used in the MARS cohort.

Corresponding Author: Robert A. Magnussen, MD, Department of Orthopaedics, Sports Health and Performance Institute, The Ohio State University, Columbus, OH 43214, robert.magnussen@ gmail.com, Phone: +1 614 366-9324, Fax: +1 614 366-9339.

${ }^{*}$ SFA Revision ACL Group: Abderahmane Sbihi, Patrick Djian, -, Christophe Hulet, Frank Jouve, Christophe Bussière, François-Paul Ehkirch, Gilles Burdin, Frédéric Dubrana, Philippe Beaufils, Jean-Pierre Franceschi, Vincent Chassaing 
Hamstring autograft was favored in the NKRL, while BTB autograft was most common in the SFA cohort. Reasons for failure of the primary ACLR were comparable, with recurrent trauma noted in 46 to $56 \%$ of patients in each of the three cohorts. Technical error was cited in 44 to $51 \%$ of patients in the MARS and SFA cohorts, but was not clearly elucidated in the NKLR cohort. Biologic failure of the primary graft was more common in the MARS cohort. Differences in associated intra-articular findings were noted at the time of revision ACLR, with significantly more high grade cartilage lesions noted in the MARS group.

Conclusions-Significant differences exist between patient populations followed in revision ACL cohorts throughout the world that should be considered when applying findings from such cohorts to different patient populations.

\section{Keywords}

Anterior cruciate ligament; reconstruction; revision; cohort; international

\section{Introduction}

Registries and multi-center prospective cohort studies are contributing more and more to our knowledge regarding anterior cruciate ligament reconstruction (ACLR). An important question is the applicability of data from one cohort to patients in other locations. Previous work has demonstrated many similarities but also significant differences in patients and operative techniques between two large cohorts of primary ACLRs: the United States-based Multicenter Orthopaedic Outcomes Network (MOON) cohort and the Norwegian Knee Ligament Registry (NKLR).[15]

The relative rarity of revision ACLR requires an even greater reliance on such multi-center studies to inform clinical decision-making. To provide such data, large cohorts of patients undergoing revision ACLR are being followed in several locations throughout the world, including the Multicenter ACL Revision Study (MARS) in North America,[21] the NKLR in Norway,[5] and the cohort of the Société Française d'Arthroscopie (SFA) in France.[22] Papers including data from large cohorts have already begun to appear regarding revision ACLR with more certainly to be published in the future.[1, 3, 14, 18, 22, 26]

The relative dearth of data regarding revision surgery has likely contributed to increased variability in practice patterns surrounding this surgery relative to primary ACLR. Therefore, a clear understanding of the similarities and differences in patients and surgical techniques used in these different cohorts will be useful to those seeking to apply the findings of these groups to their own patient populations.

The purpose of the current study is to compare the patient characteristics and surgical techniques between these cohorts of revision ACL reconstruction. We hypothesize that patient demographics, graft choice for the primary ACLR, reasons for failure of the primary reconstruction, time from primary ACLR to revision reconstruction, patient-reported outcome scores prior to revision surgery, associated intra-articular pathology at revision reconstruction, and graft choice for revision reconstruction vary among the three cohorts. 


\section{Materials and Methods}

\section{Data Collection in MARS, NKLR, and the SFA Cohort}

The MARS cohort was conceived to evaluate the outcomes of revision ACLR when it was determined that existing prospective cohorts not specifically focused on revision ACLR lacked sufficient numbers of revision cases for efficient and meaningful analysis.[21] With the backing of the American Orthopaedic Society for Sports Medicine (AOSSM), the MARS group began enrolling patients on March 1, 2006. A prospective longitudinal cohort design was established to determine prognosis and identify predictors of outcome of revision ACLR. Preoperatively, subjects complete a patient questionnaire that contains a series of validated patient-oriented outcome questionnaires including the Knee Injury and Osteoarthritis Outcome Score (KOOS),[20] Marx activity rating scale,[16] the 36-item short-form health survey (SF-36),[24] and subjective International Knee Documentation Committee (IKDC) score.[7] The surgeon completes a form detailing the injury, treatment history of the knee, associated intra-articular injuries, a detailed examination under anesthesia according to IKDC guidelines, $[6,9]$ surgical technique, and graft utilized in the revision surgery. The 87 enrolling surgeons include those in academic and private settings at 52 sites in 28 American states and 2 Canadian provinces.

The NKLR is designed to collect information prospectively on all cases of cruciate ligament reconstruction in Norway, including those patients undergoing revision ACLR. Data collected includes mechanism of injury, time since injury, intra-articular findings (meniscal and chondral pathology), method of ligament reconstruction, and treatment of any other pathology. The patients also complete the KOOS form in advance of surgery. Data regarding prior knee surgery (including the primary ACLR) is not recorded; however, these data are available if the primary reconstruction was also included in the registry. Greater than $95 \%$ of ACLRs currently performed in Norway are enrolled in the registry.[5]

The SFA revision ACL cohort was initially designed as a retrospective cohort study of all revision ACLR's between 1994 and 2003 followed by prospective data collection from 2004 to 2006. Data were collected at 10 orthopaedic centers in France. Participation was limited to patients undergoing revision ACLR with autograft following failure of a primary autograft ACLR. Preoperatively, subjects complete a subjective IKDC score. The surgeon completes a form detailing the injury, treatment history of the knee, associated intra-articular injuries, a detailed examination under anesthesia according to IKDC guidelines, surgical technique and graft utilized in the revision surgery.

\section{Retrospective Data Collection for this Analysis}

After approval was obtained from appropriate institutional review boards, de-identified data from MARS, the NKLR, and the SFA cohort were accessed. Data collected from each database included patient demographics (age, sex, height, and weight), graft choice and reason for failure of the primary ACLR, time from primary to revision ACLR, pre-revision patient-reported outcome scores (KOOS, subjective IKDC), associated intra-articular findings and treatments at revision, and graft choice for revision reconstruction. These data 
were compiled from MARS data from 2006 to 2011, NKLR data from 2004 to 2011, and SFA data from 1994 to 2006.

\section{Statistical Analysis}

Fisher's exact and chi-squared tests were utilized to compare categorical data between the three cohorts. Nonparametric methods were utilized to compare patient age and time from injury to reconstruction between the groups because these data did not fit a normal distribution. Mean and standard deviations for KOOS subscales and subjective IKDC were calculated for each database and compared using ANOVA.

\section{Results}

During the data collection period, 1216 patients were enrolled in the MARS database, 793 patients undergoing revision ACLR were recorded in the NKLR, and 277 patients were entered into the SFA revision ACL database.

The median age at the time of revision ACLR was 26 years in the MARS cohort, 28 years in the NKLR population, and 27 years in the SFA cohort (Table 1). The SFA cohort included more males $(69.1 \%)$ than the MARS $(57.8 \%)$ and NKLR $(55.8 \%)$ cohorts $(\mathrm{p}<0.0001)$. While mean height was similar between the three cohorts, mean weight and BMI were significantly different, with the MARS cohort exhibiting the highest values, followed by the NKLR and the SFA cohorts (Table 1).

\section{Primary ACLR Graft Choice}

Graft choice for the primary ACLR was available for $99.8 \%$ of MARS patients, $34.4 \%$ of NKLR patients, and $98.9 \%$ of SFA patients. The NKLR does not collect data regarding prior surgery, thus the primary graft type is only available for those patients in whom the primary reconstruction was also collected in the registry. Primary ACLR graft choice varied greatly between the three databases $(\mathrm{p}<0.0001)$ (Table 2). Bone-patellar tendon-bone (BTB) autograft was the most commonly used primary graft in the MARS cohort (40.4\%) and the SFA cohort $(70.0 \%)$, while hamstring autograft was the most common primary graft choice in the NKLR (73.6\%). Allograft was frequently utilized in the MARS cohort $(29.0 \%)$ and very rare in the NKLR $(0.4 \%)$, while the SFA cohort includes only autografts by design. Artificial grafts $(0.8 \%)$ and grafts containing both autograft and allograft tissue $(2.3 \%)$ were also present in the MARS cohort but not in the other two groups.

\section{Reason for Failure of the Primary Reconstruction}

The MARS cohort and SFA cohort both include an assessment of the reason for failure of the primary ACLR. These data are available in the NKLR database for the 482 patients $(60.8 \%)$ enrolled after 2007. Surgeons in all three groups frequently cited multiple causes of failure in the same patient. Multiple causes were cited in 35\% of patients in the MARS cohort, $12 \%$ of patients in the NKRL, and $18 \%$ of patients in the SFA cohort. Reasons for failure of the primary ACLR were comparable. Recurrent trauma noted in 46 to $56 \%$ of patients in each of the three cohorts. Technical error was cited in 45 to $51 \%$ of patients in the MARS and SFA cohorts, but was not clearly elucidated in the NKLR cohort. The NKRL 
included a category "graft failure" that was inclusive of technical errors as well as biologic failures. This reason for failure was cited in $42.7 \%$ of patients (Table 2). Biologic failure was more commonly cited in the MARS cohort (27.1\%) than in the SFA cohort (2.9\%).

\section{Time to Revision ACLR}

The median time from primary ACLR to revision ACLR was similar in the MARS (3.5 years) and SFA (3.9 years) cohorts $(\mathrm{p}=\mathrm{n} . \mathrm{s}$.). These data are not available in the NKLR database.

\section{Patient-Reported Outcome Data Prior to Revision ACLR}

Pre-revision KOOS scores were available for 1214 patients (99.8\%) in the MARS cohort and for 709 patients $(89.4 \%)$ in the NKLR cohort. Statistically significant differences between the two databases were noted in each KOOS subscale $(p \leq 0.01)$ with the MARS group scoring higher than the NKLR group on all subscales but symptoms; however, only the difference in the sport/recreation subscale exceeded the 8 points previously described as the minimum clinically significant difference (Figure 1).[19, 25] KOOS scores were not collected in the SFA cohort.

Pre-revision IKDC scores were available for 1213 patients (99.8\%) in the MARS cohort and for 219 patients (79.1\%) in the SFA cohort. The mean score in the MARS cohort (51.1) was significantly higher than in the SFA cohort (42.9) $(\mathrm{p}<0.0001)$; however, this difference does not exceed the 11.5 points that represents a clinically significant difference.[8, 25] IKDC scores were not collected in the NKLR cohort.

\section{Graft selection for Revision ACLR}

Graft choice for revision ACLR was quite variable between the three groups (Table 3). In the MARS cohort, allografts (49.4\%) and autografts (47.9\%) were used with similar frequency, with BTB autografts $(26.2 \%)$ used slightly more than hamstring autografts (20.1\%). In the NKLR, hamstring autograft (56.0\%) was the most commonly used graft followed by BTB autograft (32.4\%). Other graft types were rare. In the SFA, BTB autograft (55.9\%) was most common, followed by hamstring autograft (38.6\%). Quadriceps autografts were used in $1-2 \%$ of cases in each cohort.

\section{Meniscal Pathology and Treatment}

Medial meniscus injury was more common in the SFA (56.0\%) and MARS (45.3\%) cohorts than in the NKLR cohort $(23.7 \%)$ ( $\mathrm{p}$ <.0001). Meniscus repair was more frequent in the MARS cohort (30.3\%), followed by the NKRL (20.2\%) and SFA (12.2\%) cohorts (Figure 2). In contrast, lateral meniscus injury was most common in the MARS cohort (36.5\%) and less frequent in the NKLR $(25.1 \%)$ and SFA $(20.2 \%)$ cohorts ( $<$ 0.0001). Repair frequency was similar in the MARS (14.2\%) and NKLR (14.3\%) cohorts and rare in the SFA cohort (3.6\%) (Figure 2).

\section{Articular Cartilage Pathology}

Medial articular cartilage injury was more common in the SFA (49.1\%) and MARS (48.5\%) cohorts than in the NKRL cohort $(33.8 \%)(\mathrm{p}<0.0001)$. The distribution of medial cartilage 
injuries by severity was similar among the three cohorts, although grade IV lesions were more common in the MARS cohort than the other two groups (Figure 3).

Lateral articular cartilage injury was most common in the MARS cohort (40.4\%) and less frequent in the NKLR $(19.7 \%)$ and SFA $(23.1 \%)$ cohorts ( $\mathrm{p}<0.0001)$. There was a higher proportion of high grade (III-IV) lesions in the MARS cohort than in other two groups (Figure 3).

Patellofemoral articular cartilage injury was more common in the MARS (41.6\%) and SFA $(32.5 \%)$ cohorts than in the NKRL cohort $(15.0 \%)$ ( $\mathrm{p}<0.0001)$. There was again a higher proportion of high grade (III-IV) lesions in the MARS cohort than in other two groups (Figure 3).

\section{Discussion}

The most important findings of this study are that significant differences exist between patient populations followed in revision ACL cohorts in France, Norway, and North America. These differences include graft choice in both primary and revision ACL surgery and the prevalence of associated intra-articular pathology encountered at the time of revision ACLR.

Patient demographic factors were relatively consistent across the three studies. All three studies included significantly more males than females, with the SFA cohort demonstrating the highest percentage of males (nearly 70\%). While statistically different due to the large numbers of patients in each group, patient age was similar among the groups, with the median age in each group falling between 26 and 28 years. Similarly, BMI ranged from 23 to 26 in the three groups. Differences between the groups were statistically significant, but it remains unclear whether differences of this magnitude are clinically important.

Primary graft choice varied greatly between the groups. Most notably, primary reconstruction with allografts was much more common among revisions in the MARS group than in the NKLR. This difference reflects the much higher use of allograft in the United States than in Norway. The exact percentage of primary ACLR's in the United States that are performed with allograft tissue is unknown; however, it has been reported to be increasing.[13] It is unknown whether the proportion of primary allografts among patients undergoing revision relative is comparable to the overall proportion of primary ACLR's performed with allograft. Revision ACL graft choice also varied greatly in the three cohorts. Allograft was most common in the MARS cohort while BTB and hamstring autograft were most common in the SFA and NKLR cohorts respectively

Reasons for failure of the primary ACLR were similar between cohorts, with recurrent trauma, technical error, and multiple factors most commonly noted in both the MARS and SFA cohorts. The NKLR noted a similar risk of recurrent trauma but did not separately report biologic failures and most technical errors, limiting comparisons with the other two cohorts. The current findings are consistent with previous reports of failure etiology.[4, 10$12,23]$ Biologic failure, which has previously been reported to contribute to a very small proportion of failures,[17] was noted in over $27 \%$ of revisions in the MARS cohort. The 
increased use of allografts in primary reconstruction may contribute to this increased risk of biologic failure.

Patient reported outcomes prior to reconstruction were similar in the MARS and NKLR groups, with a clinically significant difference only noted in the sport/recreation function subscale. This finding is in contrast to prior work comparing primary ACLR's in the United States and Norway in which clinically significant differences were noted only in the symptoms subscale.[15] The reason for this difference is unclear. IKDC scores in the MARS group were significantly higher than in the SFA cohort. This difference may represent differences in the patients that choose to undergo repeat surgery in each group or be a function of the impact of cultural differences on the IKDC score.

Meniscal and articular cartilage pathology, particularly in the lateral and patellofemoral compartments, was generally higher in the MARS group. This finding may be related to the increased weight and BMI noted in the MARS group.[2] Another possibility is that increased prevalence of contact sports in the United States lead to an increase in contact ACL injuries in the MARS group and thus more associated injuries.[15] Articular cartilage and meniscal damage were commonly noted to coexist in the same compartment as has been previously reported.[3]

The strengths of this paper include its large sample size, primarily prospective data collection, and the completeness of the data sources utilized. Weaknesses include the use of some retrospectively collected data in the SFA database and some inconsistencies in data collected across the different studies. The use of more consistent patient-reported outcome scores would facilitate comparison among such databases. It should also be noted that the data collected in the MARS and especially the SFA cohort may not accurately represent the typical revision ACLR technique in the United States and France respectively given that they do not represent registry data as is present in the NKLR.

\section{Conclusion}

Significant differences exist between patient populations followed in revision ACL cohorts in France, Norway, and the North America. Differences in patient demographics as well as graft choice in both primary and revision ACL surgery and the prevalence of associated intra-articular pathology should be carefully considered by practicing clinicians when applying findings from such cohorts to their own patient population.

\section{References}

1. Borchers JR, Kaeding CC, Pedroza AD, Huston LJ, Spindler KP, Wright RW. Intra-articular findings in primary and revision anterior cruciate ligament reconstruction surgery: a comparison of the MOON and MARS study groups. Am J Sports Med. 2011; 39:1889-1893. [PubMed: 21646434]

2. Bowers AL, Spindler KP, McCarty EC, Arrigain S. Height, weight, and BMI predict intra-articular injuries observed during ACL reconstruction: evaluation of 456 cases from a prospective ACL database. Clin J Sport Med. 2005; 15:9-13. [PubMed: 15654185]

3. Brophy RH, Wright RW, David TS, McCormack RG, Sekiya JK, Svoboda SJ, Huston LJ, Haas AK, Steger-May K. Association between previous meniscal surgery and the incidence of chondral 
lesions at revision anterior cruciate ligament reconstruction. Am J Sports Med. 2012; 40:808-814. [PubMed: 22374942]

4. Carson EW, Anisko EM, Restrepo C, Panariello RA, O'Brien SJ, Warren RF. Revision anterior cruciate ligament reconstruction: etiology of failures and clinical results. J Knee Surg. 2004; 17:127-132. [PubMed: 15366266]

5. Granan LP, Bahr R, Steindal K, Furnes O, Engebretsen L. Development of a national cruciate ligament surgery registry: the Norwegian National Knee Ligament Registry. Am J Sports Med. 2008; 36:308-315. [PubMed: 17989167]

6. Hefti F, Muller W, Jakob RP, Staubli HU. Evaluation of knee ligament injuries with IKDC form. Knee Surg Sports Traumatol Arthrosc. 1993; 1:226-234. [PubMed: 8536037]

7. Irrgang JJ, Anderson AF, Boland AL, Harner CD, Kurosaka M, Neyret P, Richmond JC, Shelborne KD. Development and validation of the international knee documentation committee subjective knee form. Am J Sports Med. 2001; 29:600-613. [PubMed: 11573919]

8. Irrgang JJ, Anderson AF, Boland AL, Harner CD, Neyret P, Richmond JC, Shelbourne KD. Responsiveness of the International Knee Documentation Committee Subjective Knee Form. Am J Sports Med. 2006; 34:1567-1573. [PubMed: 16870824]

9. Irrgang JJ, Ho H, Harner CD, Fu FH. Use of the International Knee Documentation Committee guidelines to assess outcome following anterior cruciate ligament reconstruction. Knee Surg Sports Traumatol Arthrosc. 1998; 6:107-114. [PubMed: 9604196]

10. Johnson DL, Fu FH. Anterior cruciate ligament reconstruction: why do failures occur? Instr Course Lect. 1995; 44:391-406. [PubMed: 7797878]

11. Johnson, DL.; Harner, CD.; Maday, MG.; Fu, FH. Revision anterior cruciate ligament surgery. In: Fu, FH.; Harner, CD.; Vince, KG., editors. Knee Surgery. Vol. 1. Baltimore: Williams \& Wilkins; 1994. p. 977-995.

12. Johnson DL, Swenson TM, Irrgang JJ, Fu FH, Harner CD. Revision anterior cruciate ligament surgery: experience from Pittsburgh. Clin Orthop Relat Res. 1996:100-109. [PubMed: 8998862]

13. Jost PW, Dy CJ, Robertson CM, Kelly AM. Allograft use in anterior cruciate ligament reconstruction. HSS J. 2011; 7:251-256. [PubMed: 23024622]

14. Lind M, Menhert F, Pedersen AB. Incidence and outcome after revision anterior cruciate ligament reconstruction: results from the Danish registry for knee ligament reconstructions. Am J Sports Med. 2012; 40:1551-1557. [PubMed: 22562791]

15. Magnussen RA, Granan LP, Dunn WR, Amendola A, Andrish JT, Brophy R, Carey JL, Flanigan D, Huston LJ, Jones M, Kaeding CC, McCarty EC, Marx RG, Matava MJ, Parker RD, Vidal A, Wolcott M, Wolf BR, Wright RW, Spindler KP, Engebretsen L. Cross-cultural comparison of patients undergoing ACL reconstruction in the United States and Norway. Knee Surg Sports Traumatol Arthrosc. 2010; 18:98-105. [PubMed: 19784630]

16. Marx RG, Stump TJ, Jones EC, Wickiewicz TL, Warren RF. Development and evaluation of an activity rating scale for disorders of the knee. Am J Sports Med. 2001; 29:213-218. [PubMed: 11292048]

17. Menetrey J, Duthon VB, Laumonier T, Fritschy D. "Biological failure" of the anterior cruciate ligament graft. Knee Surg Sports Traumatol Arthrosc. 2008; 16:224-231. [PubMed: 18183368]

18. Morgan JA, Dahm D, Levy B, Stuart MJ. Femoral Tunnel Malposition in ACL Revision Reconstruction. J Knee Surg. 2012; 25:361-368. [PubMed: 23150344]

19. Roos EM, Lohmander LS. The Knee injury and Osteoarthritis Outcome Score (KOOS): from joint injury to osteoarthritis. Health Qual Life Outcomes. 2003; 1:64. [PubMed: 14613558]

20. Roos EM, Roos HP, Lohmander LS, Ekdahl C, Beynnon BD. Knee Injury and Osteoarthritis Outcome Score (KOOS)--development of a self-administered outcome measure. J Orthop Sports Phys Ther. 1998; 28:88-96. [PubMed: 9699158]

21. Spindler KP. The Multicenter ACL Revision Study (MARS): a prospective longitudinal cohort to define outcomes and independent predictors of outcomes for revision anterior cruciate ligament reconstruction. J Knee Surg. 2007; 20:303-307. [PubMed: 17993074]

22. Trojani C, Beaufils P, Burdin G, Bussiere C, Chassaing V, Djian P, Dubrana F, Ehkirch FP, Franceschi JP, Hulet C, Jouve F, Potel JF, Sbihi A, Neyret P, Colombet P. Revision ACL 
reconstruction: influence of a lateral tenodesis. Knee Surg Sports Traumatol Arthrosc. 2012; 20:1565-1570. [PubMed: 22102009]

23. Uribe JW, Hechtman KS, Zvijac JE, Tjin ATEW. Revision anterior cruciate ligament surgery: experience from Miami. Clin Orthop Relat Res. 1996:91-99. [PubMed: 8998902]

24. Ware JE Jr, Sherbourne CD. The MOS 36-item short-form health survey (SF-36). I. Conceptual framework and item selection. Med Care. 1992; 30:473-483. [PubMed: 1593914]

25. Wright RW. Knee injury outcomes measures. J Am Acad Orthop Surg. 2009; 17:31-39. [PubMed: 19136425]

26. Wright RW, Huston LJ, Spindler KP, Dunn WR, Haas AK, Allen CR, Cooper DE, DeBerardino TM, Lantz BB, Mann BJ, Stuart MJ. Descriptive epidemiology of the Multicenter ACL Revision Study (MARS) cohort. Am J Sports Med. 2010; 38:1979-1986. [PubMed: 20889962]

\section{The MARS Group}

\begin{tabular}{|c|c|}
\hline John P. Albright, MD & University of Iowa Hospitals and Clinics \\
\hline Christina R. Allen, MD & University of California, San Francisco \\
\hline Annunziato Amendola, MD & University of Iowa Hospitals and Clinics \\
\hline Allen F. Anderson, MD & Tennessee Orthopaedic Alliance \\
\hline Jack T. Andrish, MD & Cleveland Clinic \\
\hline Christopher C. Annunziata, MD & Commonwealth Orthopaedics \& Rehab \\
\hline Robert A. Arciero, MD & University of Connecticut Health Center \\
\hline Bernard R. Bach Jr, MD & Rush University Medical Center \\
\hline Champ L. Baker, III, MD & The Hughston Clinic \\
\hline Arthur R. Bartolozzi, MD & 3B Orthopaedics, University of Pennsylvania Health System \\
\hline Keith M. Baumgarten, MD & Orthopedic Institute \\
\hline Jeffery R. Bechler, MD & University Orthopedic Associates, LLC \\
\hline Jeffrey H. Berg, MD & Town Center Orthopaedic Associates \\
\hline Geoffrey A. Bernas, MD & State University of New York at Buffalo \\
\hline Stephen F. Brockmeier, MD & University of Virginia \\
\hline Robert H. Brophy, MD & Washington University, St. Louis \\
\hline Charles A. Bush-Joseph, MD & Rush University Medical Center \\
\hline J. Brad Butler, V, MD & Orthopedic and Fracture Clinic \\
\hline John D. Campbell, MD & Bridger Orthopaedic and Sports Medicine \\
\hline James L. Carey, M.D., M.P.H. & University of Pennsylvania, Philadelphia, PA \\
\hline James E. Carpenter, MD & University of Michigan \\
\hline Brian J. Cole, MD & Rush University Medical Center \\
\hline Daniel E. Cooper, MD & W.B. Carrell Memorial Clinic \\
\hline Jonathan M. Cooper, DO & HealthPartners Specialty Clinic \\
\hline Charles L. Cox, MD & Vanderbilt University \\
\hline R. Alexander Creighton, MD & University of North Carolina Medical Center \\
\hline Diane L. Dahm, MD & Mayo Clinic Rochester \\
\hline Tal S. David, MD & Arthroscopic and Orthopedic Sports Medicine Associates \\
\hline Thomas M. DeBerardino, MD & University of Connecticut Health Center \\
\hline Warren R. Dunn, MD, MPH & Vanderbilt University \\
\hline David C. Flanigan, MD & The Ohio State University \\
\hline Robert W. Frederick, MD & The Rothman Institute/Thomas Jefferson University \\
\hline
\end{tabular}

Knee Surg Sports Traumatol Arthrosc. Author manuscript; available in PMC 2016 August 01. 


\begin{tabular}{|c|c|}
\hline Theodore J. Ganley, MD & The Children's Hospital of Philadelphia \\
\hline Charles J. Gatt, Jr., MD & University Orthopedic Associates, LLC \\
\hline Steven R. Gecha, MD & Princeton Orthopaedic Associates \\
\hline James Robert Giffin, MD & University of Western Ontario \\
\hline Amanda K. Haas, M.A. & Washington University, St. Louis, MO \\
\hline Sharon L. Hame, MD & David Geffen School of Medicine at UCLA \\
\hline Jo A. Hannafin, MD, PhD & Hospital for Special Surgery \\
\hline Christopher D. Harner, MD & University of Pittsburgh Medical Center \\
\hline Norman Lindsay Harris, Jr., MD & Orthopaedic Associates of Aspen \& Glenwood \\
\hline Keith S. Hechtman, MD & UHZ Sports Medicine Institute \\
\hline Elliott B. Hershman, MD & Lenox Hill Hospital \\
\hline Rudolf G. Hoellrich, MD & Slocum Research and Education Foundation \\
\hline Timothy M. Hosea, MD & University Orthopedic Associates, LLC \\
\hline Laura J. Huston, M.S. & Vanderbilt University, Nashville, TN \\
\hline David C. Johnson, MD & National Sports Medicine Institute \\
\hline Timothy S. Johnson, MD & National Sports Medicine Institute \\
\hline Morgan H. Jones, MD & Cleveland Clinic \\
\hline Christopher C. Kaeding, MD & The Ohio State University \\
\hline Ganesh V. Kamath, MD & University of North Carolina Medical Center \\
\hline Thomas E. Klootwyk, MD & Methodist Sports Medicine Center-The Orthopedic Specialists \\
\hline Brett (Brick) A. Lantz, MD & Slocum Research and Education Foundation \\
\hline Bruce A. Levy, MD & Mayo Clinic Rochester \\
\hline C. Benjamin Ma, MD & University of California, San Francisco \\
\hline G. Peter Maiers, II, MD & Methodist Sports Medicine Center-The Orthopedic Specialists \\
\hline Barton Mann, PhD & American Orthopaedic Society for Sports Medicine \\
\hline Robert G. Marx, MD & Hospital for Special Surgery \\
\hline Matthew J. Matava, MD & Washington University, St. Louis \\
\hline Gregory M. Mathien, MD & Knoxville Orthopedic Clinic \\
\hline David R. McAllister, MD & David Geffen School of Medicine at UCLA \\
\hline Eric C. McCarty, MD & University of Colorado Denver School of Medicine \\
\hline Robert G. McCormack, MD & University of British Columbia \\
\hline Bruce S. Miller, MD, MS & University of Michigan \\
\hline Carl W. Nissen, MD & Connecticut Children's Medical Center \\
\hline Daniel F. O'Neill, MD, Ed.D & Littleton Regional Hospital \\
\hline LTC Brett D. Owens, MD & Keller Army Community Hospital-United States Military Academy \\
\hline Richard D. Parker, MD & Cleveland Clinic \\
\hline Mark L. Purnell, MD & Orthopaedic Associates of Aspen \& Glenwood \\
\hline Arun J. Ramappa, MD & Beth Israel Deaconess Medical Center \\
\hline Michael A. Rauh, MD & State University of New York at Buffalo \\
\hline Arthur Rettig, MD & Methodist Sports Medicine Center-The Orthopedic Specialists \\
\hline Jon K. Sekiya, MD & University of Michigan \\
\hline Kevin G. Shea, MD & Intermountain Orthopedics \\
\hline Orrin H. Sherman, MD & NYU Hospital for Joint Diseases \\
\hline
\end{tabular}

Knee Surg Sports Traumatol Arthrosc. Author manuscript; available in PMC 2016 August 01. 


\begin{tabular}{ll} 
James R. Slauterbeck, MD & University of Vermont College of Medicine \\
Matthew V. Smith, MD & Washington University, St. Louis \\
Jeffrey T. Spang, MD & University of North Carolina Medical Center \\
Kurt P. Spindler, MD & Vanderbilt University \\
Michael J. Stuart, MD & Mayo Clinic Rochester \\
LTC. Steven J. Svoboda, MD & Keller Army Community Hospital-United States Military Academy \\
Timothy N. Taft, MD & University of North Carolina Medical Center \\
COL Joachim J. Tenuta, MD & Keller Army Community Hospital-United States Military Academy \\
Edwin M. Tingstad, MD & Inland Orthopaedics/Washington State University \\
Armando F. Vidal, MD & University of Colorado Denver School of Medicine \\
Darius G. Viskontas, MD & University of British Columbia, Royal Columbian Hospital \\
Richard A. White, MD & University of Missouri-Columbia \\
James S. Williams Jr., MD & Cleveland Clinic \\
Michelle L. Wolcott, MD & University of Colorado Denver School of Medicine \\
Brian R. Wolf, MD & University of Iowa Hospitals and Clinics \\
James J. York, MD & Chesapeake Orthopaedics \& Sports Medicine Center \\
\hline
\end{tabular}

Knee Surg Sports Traumatol Arthrosc. Author manuscript; available in PMC 2016 August 01. 


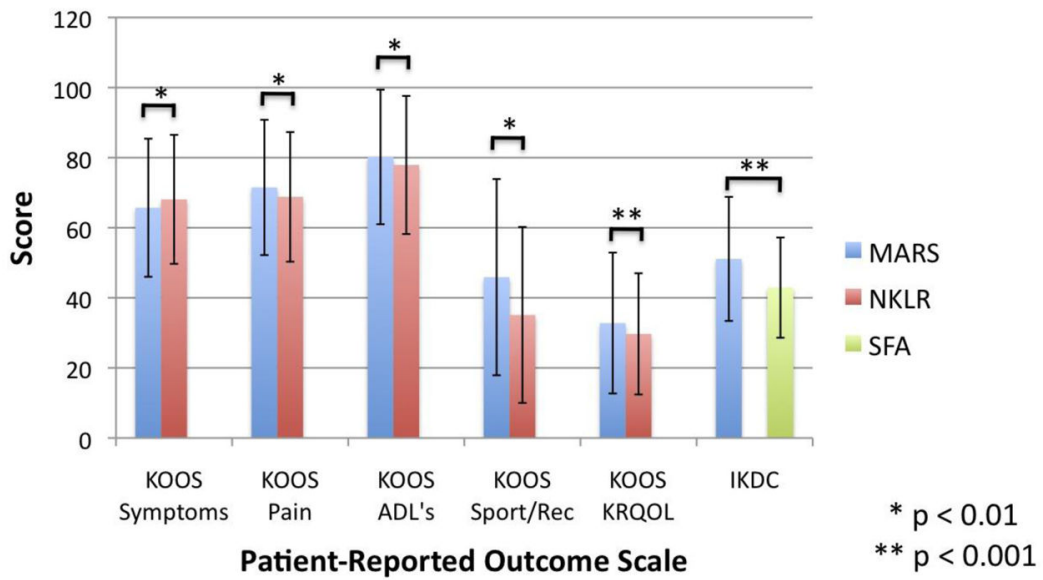

Figure 1.

Pre-revision patient-reported outcomes scores (KOOS and IKDC) for patients in the MARS, NKLR, and SFA cohorts. No KOOS data are available for the SFA cohort and no IKDC scores are available for the NKLR cohort. 


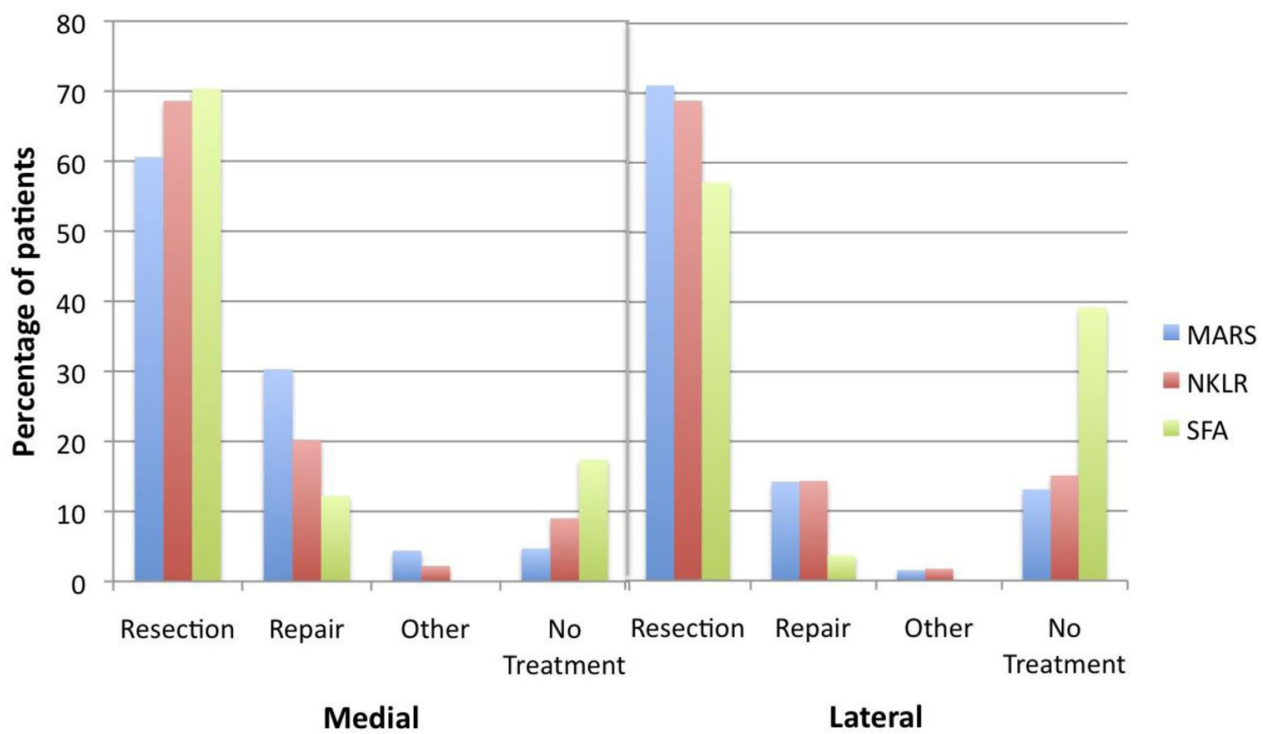

Figure 2.

Treatment of patients with medial and lateral meniscus pathology in the MARS, NKLR, and SFA cohorts. 


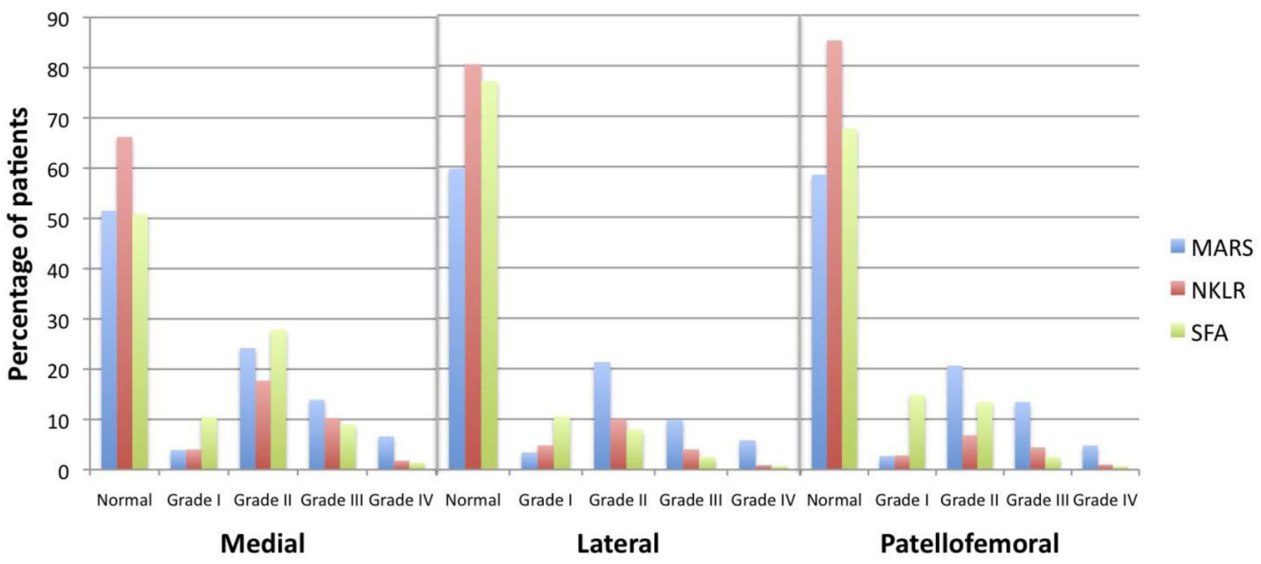

Figure 3.

The incidence of medial, lateral, and patellofemoral compartment chondral damage at the time of revision ACL reconstruction 


\section{Table 1}

Patient Demographics (at revision ACL reconstruction)

\begin{tabular}{|c|c|c|c|c|}
\hline & MARS & NKLR & SFA & Significance \\
\hline Age (years) (median, IQR) & $26(20-34)$ & $28(21-37)$ & $27(23-32)$ & $\begin{array}{l}\text { overall } \mathbf{p}<0.0001 \\
\text { M v. } \mathbf{N}<<0.0001 \\
\text { M v. S p = 0.019 } \\
\text { N v. S p = n.s. }\end{array}$ \\
\hline Sex (percent male) & $57.8 \%$ & $55.8 \%$ & $69.1 \%$ & $\mathrm{p}<0.0001$ \\
\hline Height $(m)($ mean \pm SD $)$ & $1.74 \pm 0.09$ & $1.75 \pm 0.09$ & $1.73 \pm 0.08$ & overall $\mathrm{p}=$ n.s. \\
\hline Weight $(\mathrm{kg})($ mean $\pm \mathrm{SD})$ & $80.1 \pm 18.0$ & $77.0 \pm 14.9$ & $71.0 \pm 13.4$ & $\begin{array}{l}\text { overall } p<0.0001 \\
\text { M v. } \mathbf{N}=0.014 \\
\text { M v. } S p<0.0001 \\
\text { N v. } S p<0.0001\end{array}$ \\
\hline $\mathrm{BMI}\left(\mathrm{kg} / \mathrm{m}^{2}\right)($ mean $\pm \mathrm{SD})$ & $26.1 \pm 4.6$ & $24.9 \pm 4.2$ & $23.5 \pm 3.3$ & $\begin{array}{l}\text { overall } p<0.0001 \\
\text { M v. } \mathbf{p}=0.0001 \\
\text { M v. S p }<0.0001 \\
\text { N v. } S p<0.0001\end{array}$ \\
\hline
\end{tabular}

MARS = Multicenter ACL Revision Study

NKLR $=$ Norwegian Knee Ligament Registry

SFA = Société Française d'Arthroscopie

$\mathrm{IQR}=$ Inter-quartile Range

$\mathrm{M}=$ MARS

$\mathrm{N}=\mathrm{NKLR}$

$\mathrm{S}=\mathrm{SFA}$

$\mathrm{SD}=$ Standard Deviation 
Table 2

Primary ACL Reconstruction Data

\begin{tabular}{|c|c|c|c|c|}
\hline & $\operatorname{MARS}(n=1216)$ & NKLR n = variable ${ }^{\#}$ & SFA $(n=277)$ & Significance \\
\hline Graft Choice & & $\mathrm{n}=284$ & & $\mathrm{p}<0.0001$ \\
\hline BTB autograft & $491(40.4 \%)$ & $63(30.1 \%)$ & $194(70.0 \%)$ & \\
\hline Hamstring autograft & $317(26.1 \%)$ & $209(73.6 \%)$ & $73(26.4 \%)$ & \\
\hline Quadriceps autograft & $6(0.5 \%)$ & & $7(2.5 \%)$ & \\
\hline Other & $7(0.6 \%)$ & & & \\
\hline Allograft & $353(29.0 \%)$ & $1(0.4 \%)$ & & \\
\hline Hybrid & $29(2.3 \%)$ & & & \\
\hline Artificial & $10(0.8 \%)$ & & & \\
\hline Not reported & $3(0.2 \%)$ & $11(3.9 \%)$ & $3(1.1 \%)$ & \\
\hline Reason for failure of primary reconstruction ${ }^{*}$ & & $\mathrm{n}=482$ & & $\mathrm{p}<0.0001$ \\
\hline Technical error & $618(50.8 \%)$ & & $124(44.8 \%)$ & \\
\hline Traumatic & $680(55.9 \%)$ & $226(46.9 \%)$ & $128(46.2 \%)$ & \\
\hline Biologic & $330(27.2 \%)$ & & $8(2.9 \%)$ & \\
\hline Infection & $3(0.2 \%)$ & $7(2.5 \%)$ & $2(0.7 \%)$ & \\
\hline "Graft Failure" & & $206(42.7 \%)$ & & \\
\hline Other & $34(3 \%)$ & $49(10.2 \%)$ & & \\
\hline Not reported & $2(0.2 \%)$ & $53(11.0 \%)$ & $66(23.8 \%)$ & \\
\hline Median time from primary reconstruction to revision (years) & $\begin{array}{l}3.5 \\
\text { IQR: } 1.5-8.4\end{array}$ & NR & IQR: $\begin{array}{l}3.9 \\
2.1-6.6\end{array}$ & $\mathrm{p}=\mathrm{n} . \mathrm{s}$ \\
\hline
\end{tabular}

\# Number of patients in the NKRL for whom primary reconstruction data were available varied. Data regarding primary graft choice were available in 284 patients in whom the primary reconstruction was performed after 2004. Data regarding reason for failure of the primary reconstruction were available in the 482 patients enrolled after 2007.

The total of percentages exceeds $100 \%$ because surgeons were allowed to document multiple causes for failure of primary ACL reconstruction.

MARS = Multicenter ACL Revision Study

NKLR $=$ Norwegian Knee Ligament Registry

SFA = Société Française d'Arthroscopie

BTB $=$ Bone-Patellar Tendon-Bone

$\mathrm{NR}=$ Not Reported

$\mathrm{IQR}=$ Inter-quartile Range 


\section{Table 3}

Revision ACL Reconstruction Data

\begin{tabular}{|l|c|c|c|l|}
\hline & MARS $(\mathbf{n}=\mathbf{1 2 1 6})$ & NKLR $(\mathbf{n}=\mathbf{7 9 3})$ & SFA (n= 277) & Significance \\
\hline Graft Choice & & & & $\mathbf{p}<\mathbf{0 . 0 0 0 1}$ \\
\hline BTB autograft & $318(26.2 \%)$ & $257(32.4 \%)$ & $155(55.9 \%)$ & \\
\hline Hamstring autograft & $245(20.1 \%)$ & $444(56.0 \%)$ & $107(38.6 \%)$ & \\
\hline Quadriceps autograft & $19(1.6 \%)$ & $13(1.6 \%)$ & $6(2.2 \%)$ & \\
\hline Other & $1(0.1 \%)$ & $5(0.6 \%)$ & $6(2.2 \%)$ & \\
\hline Allograft & $601(49.4 \%)$ & $30(3.8 \%)$ & & \\
\hline Hybrid & $32(2.6 \%)$ & & & \\
\hline Not Reported & & $44(5.5 \%)$ & $3(1.1 \%)$ & \\
\hline Medial meniscus injury & $551(45.3 \%)$ & $188(23.7 \%)$ & $155(56.0 \%)$ & $\mathbf{p}<\mathbf{0 . 0 0 0 1}$ \\
\hline Lateral meniscus injury & $444(36.5 \%)$ & $119(25.1 \%)$ & $56(20.2 \%)$ & $\mathbf{p}<\mathbf{0 . 0 0 0 1}$ \\
\hline Medial articular cartilage injury & $590(48.5 \%)$ & $268(33.8 \%)$ & $136(49.1 \%)$ & $\mathbf{p}<\mathbf{0 . 0 0 0 1}$ \\
\hline Lateral articular cartilage injury & $491(40.4 \%)$ & $156(19.7 \%)$ & $64(23.1 \%)$ & $\mathbf{p}<\mathbf{0 . 0 0 0 1}$ \\
\hline Patellofemoral articular cartilage injury & $506(41.6 \%)$ & $119(15.0 \%)$ & $90(32.5 \%)$ & $\mathbf{p}<\mathbf{0 . 0 0 0 1}$ \\
\hline
\end{tabular}

MARS $=$ Multicenter ACL Revision Study

NKLR $=$ Norwegian Knee Ligament Registry

SFA = Société Française d'Arthroscopie

$\mathrm{BTB}=$ Bone-Patellar Tendon-Bone 